\title{
Inverse gas chromatography analysis of spruce fibers with different lignin content
}

\author{
Simona Peterlin • Odon Planinšek • \\ Isabel Moutinho $\cdot$ Paulo Ferreira $\cdot$ Darko Dolenc
}

Received: 10 May 2010/Accepted: 7 August 2010

(C) Springer Science+Business Media B.V. 2010

\begin{abstract}
Unbleached TMP spruce fibers were stepwise delignified by $\mathrm{KMnO}_{4} / \mathrm{H}_{2} \mathrm{SO}_{4}$ and five partly delignified samples were obtained. Fibers were characterized in terms of carboxylic groups, lignin and hemicelluloses content. IGC measurements were performed in the untreated fibers and in the five delignified fiber samples, as well as in microcrystalline cellulose (MCC). Different parameters, such as the dispersive component of the surface free energy $\left(\gamma_{s}^{d}\right)$, the free energy and the enthalpy of adsorption with nonpolar probes $\left(\Delta G_{a}^{d}\right.$ and $\Delta H_{a}^{d}$, respectively), as well as the specific interactions with polar probes,
\end{abstract}

S. Peterlin

Pulp and Paper Institute, Bogišičeva 8, 1000 Ljubljana,

Slovenia

O. Planinšek

Faculty of Pharmacy, University of Ljubljana,

Aškerčeva 7, 1000 Ljubljana, Slovenia

I. Moutinho

Portucel Soporcel Group, Complexo Industrial de Setúbal,

Apartado 55, 2901-861 Setúbal, Portugal

P. Ferreira

Chemical Engineering Department, Coimbra University,

Polo II-Rua Silvio Lima, 3030-790 Coimbra, Portugal

D. Dolenc $(\bowtie)$

Faculty of Chemistry and Chemical Technology,

University of Ljubljana, Aškerčeva 5, 1000 Ljubljana,

Slovenia

e-mail: darko.dolenc@fkkt.uni-lj.si quantified by the free energy and the enthalpy of adsorption $\left(\Delta G_{a}^{s}\right.$ and $\Delta H_{a}^{s}$, respectively), were determined. The values of $\gamma_{s}^{d}$ and $\Delta G_{a}^{d}$ are for all samples lower than for pure cellulose and vary slightly with the amount of lignin. For small contents of lignin, the values of $\Delta G_{a}^{s}$ of the acidic probes decrease with the delignification whereas those of the basic probes increase, pointing to a rather acidic character of the fibers due to the increase of the relative amount of the carbohydrates. The values for MCC corroborate these findings. Despite the substantial variation in the carboxylic group content during delignification, no clear tendencies were detected regarding the affinity with the basic probes.

Keywords Wood fibers - Delignification - Lignin · Hemicelluloses - Inverse gas chromatography

\section{Introduction}

Inverse gas chromatography (IGC) is an efficient and accurate method for the physicochemical surface characterization of some materials, used for instance in pharmacy, polymer and particle technology, coatings, pulps and papers. The use of various nonpolar and polar probes, interacting with a given surface, enables the assessment of several surface free energy related parameters, such as its dispersive component and the specific, acceptor-donor or acidic-basic properties. 
Inverse gas chromatography has been used by several authors for studying different types of papermaking fibers like unbleached and bleached hardwood and softwood chemical pulp fibers (Abdmziem et al. 2006; Belgacem 2000; Carvalho et al. 2005a; Carvalho et al. 2005b; Felix and Gatenholm 1993; Jacob and Berg 1994; Shen et al. 1998; Shen and Parker 1999), chemi-thermomechanical pulp fibers (Jacob and Berg 1994; Börås et al. 1997, Kamdem and Riedl 1991) and thermomechanical pulp fibers (Dorris and Gray 1980). Various samples used as reference material for pure cellulose, like cotton fibers (Shen and Parker 1999; Dorris and Gray 1980; Buschle-Diller et al. 2005), microcrystalline cellulose (Abdmziem et al. 2006; Jacob and Berg 1994; Belgacem et al. 1996) and a powder of hardwood $\alpha$-cellulose fibers (Belgacem et al. 1995) were also extensively examined. Lignin rich fiber samples with different lignin contents were compared by using IGC (Shen and Parker 1999; Belgacem et al. 1996).

The authors of the present study have been involved in evaluating the adsorption characteristics of fibers with distinct surface compositions (in terms of lignin, hemicelluloses and cellulose), by using cationic dyes with selected structural properties (Peterlin et al. 2009). For that purpose, pulp fibers with decreasing amounts of lignin, obtained by stepwise oxidative delignification with acidic permanganate, were prepared. This atypical delignification laboratory procedure was applied to selectively remove lignin and preserve the carbohydrates as much as possible undamaged and, simultaneously, more and more exposed (Li and Gellerstedt 1998a, b). Since it is known that adsorption depends on the presence and concentration of certain functional groups at the fiber surface which possess electron donor/acceptor abilities, it was decided to compare the results with those obtained by IGC, in order to get a deeper insight on the fibers surface chemistry and a better understanding of the complex interactions of the dye molecules with the fibers. Although IGC utilizes as probes compounds with small and simple molecules which are not directly comparable to the larger and usually ionic molecules of the dyes, it was decided to use the technique for the fibers surface characterization, in order to find out whether the results could add for interpreting the dye adsorption characteristics.

\section{Materials and methods}

An unbleached Norway spruce thermomechanical pulp with kappa number 134, sampled in a Swedish mill, was used as initial fiber sample. This sample was stepwise oxidized with an acidic potassium permanganate solution and five samples with various lignin contents, corresponding kappa numbers of 107, 75, $33,17,5$, were prepared. The lignin content of pulp samples was determined according to the TAPPI $\mathrm{T}$ 236 om-99 standard method and reported in terms of kappa number. After oxidation the pulp samples were exhaustively washed with deionized water at $60{ }^{\circ} \mathrm{C}$ in order to remove all dissolved and colloidal substances and then washed with deionized (miliQ) water until the conductivity was lower than $2 \mu \mathrm{S} \mathrm{cm}^{-1}$. After washing, samples were filtered and stored at $5{ }^{\circ} \mathrm{C}$ for further analyses. A powder of microcrystalline cellulose (Cellulose powder DS-0 Fluka) was used as a pure cellulose reference material.

The carboxylic acid group content was determined by conductometric titration according to the SCANCM 65:02 standard method.

The carbohydrate content of hemicelluloses and pectins was quantified by acid methanolysis followed by derivatization and gas chromatography analysis (Sundberg et al. 1996).

The inverse gas chromatography measurements were carried out using the Agilent Technologies $6890 \mathrm{~N}$ (USA) gas chromatograph equipped with a flame ionization detector. The injector and detector were operated at 150 and $250{ }^{\circ} \mathrm{C}$, respectively. The flow rate of the carrier gas (helium 5.0, Messer, Slovenia) was set at $5 \mathrm{~mL} \mathrm{~min}{ }^{-1}$.

The fluffed fiber materials were packed into glass chromatographic columns with $4 \mathrm{~mm}$ inner diameter and $0.3 \mathrm{~m}$ length. The columns were washed with distilled water and acetone before packing. The packed columns were conditioned overnight at $60{ }^{\circ} \mathrm{C}$ under a constant stream of helium with a flow rate of $5 \mathrm{~mL} \mathrm{~min}{ }^{-1}$ to remove volatile molecules adsorbed at the stationary phase surface, which could affect the retention of the probe molecules. IGC measurements at infinite dilution were performed at five column temperatures $\left(30,35,40,45\right.$ and $\left.50{ }^{\circ} \mathrm{C}\right)$, with two replicates for each temperature.

To determine the dead volume of the column methane was used as a non-interacting reference 
Fig. 1 The content of hemicelluloses and carboxylic groups during delignification

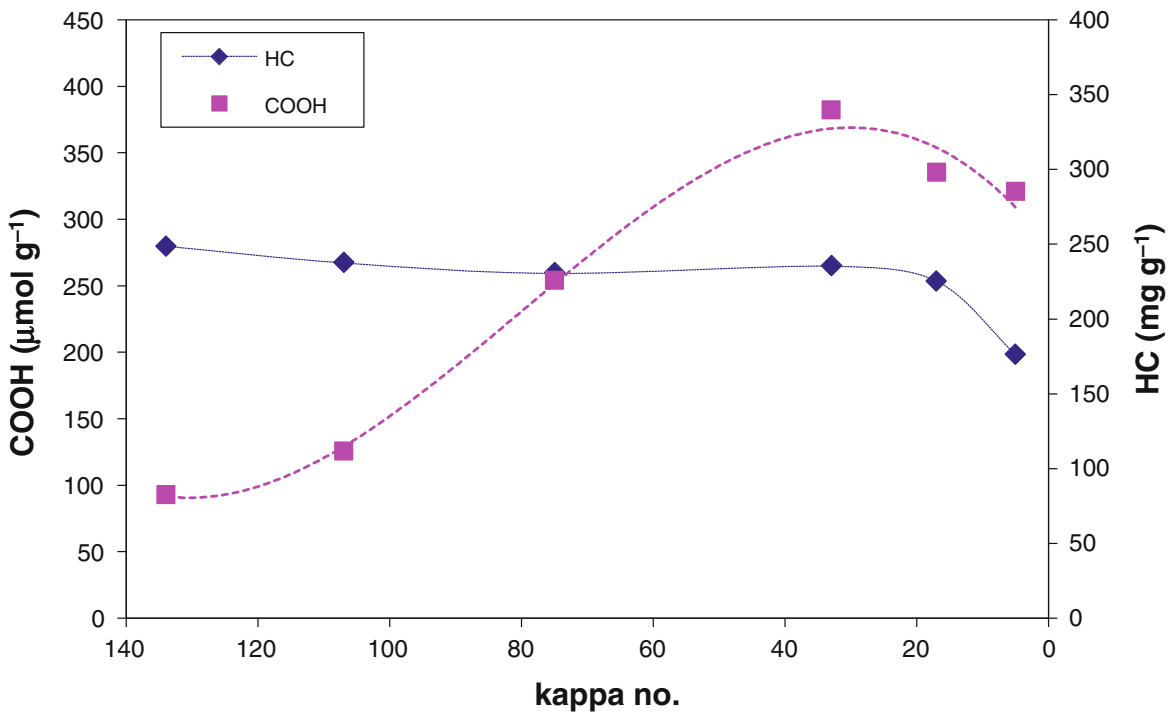

probe. All probes were used at analytical grade without further purification. The nonpolar probes used were $n$-hexane, $n$-heptane, $n$-octane, $n$-nonane, $n$-decane. The polar probes were tetrahydrofuran (THF) as basic probe, ethyl acetate $\left(\right.$ EtOAc) ${ }^{1}$ and acetone (MeCOMe) as amphoteric probes, and chloroform $\left(\mathrm{CHCl}_{3}\right)$ and dichloromethane $\left(\mathrm{CH}_{2} \mathrm{Cl}_{2}\right)$ as acidic probes.

The physicochemical properties of all probes used in IGC calculations and the theory of IGC are given elsewhere (Belgacem 2000; Carvalho et al. 2005a; Jacob and Berg 1994; Shen and Parker 1999; Dorris and Gray 1980; Fowkes 1987; Kunaver et al. 2004; Matuana et al. 1999; Santos et al. 2002, Santos and Guthrie 2005, Schultz et al. 1987).

\section{Results and discussion}

Determination of hemicelluloses and carboxylic groups

During pulp delignification, the content of lignin decreased steadily, whereas the content of

\footnotetext{
${ }^{1}$ Ethyl acetate is regarded by most authors as an amphoteric probe. However, in the measurements presented in this paper, its behavior resembles more closely basic THF than amphoteric acetone, Figs 6 and 7. See also Jacob and Berg (1994).
}

hemicelluloses remained nearly constant until the last sample (Fig. 1). The plausible explanation for this is the reaction of hemicelluloses with the acidic permanganate when there is not enough lignin to react with and therefore they become exposed to the attack of permanganate ( $\mathrm{Li}$ and Gellerstedt 1998a). As for the amount of carboxylic groups, there is an initial increase as a consequence of the oxidation of the lignin aromatic structures, followed by a decrease when the total amount of lignin becomes very low (Fig. 1).

Determination of the dispersive component of the surface free energy of the fibers

The dispersive component of the surface energy, $\gamma_{s}^{d}$, determined by IGC in the temperature range $30-50{ }^{\circ} \mathrm{C}$ decrease linearly with temperature, as expected (Fig. 2) (Carvalho et al. 2005a, Shen et al. 1998, Santos et al. 2001). The slopes of the lines are negative and their absolute values generally increase with the progress of lignin removal, as can be confirmed from the results obtained at $40{ }^{\circ} \mathrm{C}$ (Table 1) (The pulp with kappa number 75 is however, an outlier).

The value of $\gamma_{s}^{d}$ for microcrystalline cellulose is considerably higher than those of the tested fiber samples and also higher than the literature values for cellulose and hemicelluloses rich fibers such as bleached pulps. Nevertheless, it coincides fairly well with the literature data (Table 2). 


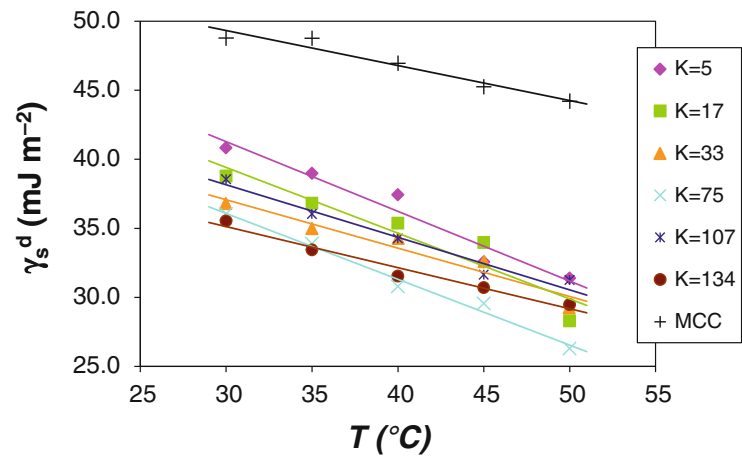

Fig. 2 Temperature dependence of the dispersive component of the surface energy of TMP fiber samples with distinct kappa numbers $(\mathrm{K})$ and of microcrystalline cellulose

Table $1 \gamma_{s}^{d}$ values of fiber samples at $40{ }^{\circ} \mathrm{C}$

\begin{tabular}{lll}
\hline Kappa number & $\gamma_{s}^{d}\left(\mathrm{~mJ} \mathrm{~m}^{-2}\right)$ & $\mathrm{d} \gamma_{s}^{d} / \mathrm{d} T\left(\mathrm{~mJ} \mathrm{~m}^{-2} \mathrm{~K}^{-1}\right)$ \\
\hline 134 & 32.2 & -0.30 \\
107 & 34.4 & -0.38 \\
75 & 31.3 & -0.48 \\
33 & 33.6 & -0.35 \\
17 & 34.7 & -0.48 \\
5 & 36.2 & -0.51 \\
$\mathrm{MCC}^{\text {a }}$ & 46.8 & -0.25 \\
\hline
\end{tabular}

${ }^{a}$ Microcrystalline cellulose (Cellulose powder DS-0 Fluka)

For all tested temperatures, and with few exceptions, the values plotted in Fig. 2 are smaller than those reported in the literature (Table 2). One reasonable explanation is that the methodology used in the present study for the fiber delignification leads in its early stages merely to the thinning of the lignin layer and the carbohydrates remain more or less buried. Only when the content of lignin decreases to a very small value, the carbohydrates become increasingly exposed, thus contributing to the higher values close to those of the TMP and bleached kraft pulps listed in Table 2 for the same temperatures.

Even for the lignin rich fibers (higher kappa numbers), the $\gamma^{d}$ values do not match those of the isolated lignins reported in the literature. The most logical explanation is that the isolated lignins are chemically modified and their properties are considerably altered (Forss and Fremer 2000; Kubo and Kadla 2005).
Table $2 \gamma_{s}^{d}$ values of different pulp samples, MCC and lignins

\begin{tabular}{lll}
\hline Sample & $\gamma_{s}^{d}\left(\mathrm{~mJ} \mathrm{~m}^{-2}\right)$ & $T\left({ }^{\circ} \mathrm{C}\right)$ \\
\hline TMP & 38.8 & $30^{\mathrm{a}}$ \\
Norway spruce wood & 42 & $20^{\mathrm{b}}$ \\
CTMP & 25.2 & $40^{\mathrm{c}}$ \\
Unbleached pulps & $38-42$ & $37^{\mathrm{d}}$ \\
Bleached kraft pulp & 38.4 & $40^{\mathrm{e}}$ \\
& 45.0 & $40^{\mathrm{f}}$ \\
& 41.3 & $40^{\mathrm{g}}$ \\
Bleached sulfite pulp & 44.0 & $-^{\mathrm{h}}$ \\
Filter paper & 56.6 & $37^{\mathrm{d}}$ \\
Cotton cell. paper & 49.9 & $40^{\mathrm{a}}$ \\
$\alpha-$ Hardwood cell. & 31.9 & $40^{\mathrm{i}}$ \\
$\alpha-$ Hard. cell. extract. & 47.4 & $40^{\mathrm{i}}$ \\
MCC & 40.3 & $50^{\mathrm{j}}$ \\
& 52.3 & $39^{\mathrm{k}}$ \\
Isolated lignins & & \\
Organosolv & 44.7 & $50^{\mathrm{j}}$ \\
Kraft & 46.6 & $50^{\mathrm{j}}$ \\
Steam explosion & 49.0 & $50^{\mathrm{j}}$ \\
Soda lignin & 48.2 & $37^{\mathrm{d}}$ \\
Polystyrene & 43.3 & $45^{1}$ \\
\hline
\end{tabular}

a Dorris and Gray 1980, ${ }^{\mathrm{b}}$ Wålinder and Gardner 2000, c Kamdem and Riedl 1991, ${ }^{\mathrm{d}}$ Shen and Parker 1999, ${ }^{\mathrm{e}}$ Shen et al. 1998, ${ }^{\mathrm{f}}$ Carvalho et al. 2005a, ${ }^{\mathrm{g}}$ Carvalho et al. 2005b, h Felix and Gatenholm 1993, i Belgacem et al. 1995,

${ }^{\mathrm{j}}$ Belgacem et al. 1996, ${ }^{\mathrm{k}}$ Papirer et al. 2000, ${ }^{1}$ Tze et al. 2006

Determination of the free energy and enthalpy of adsorption of the nonpolar probes on the fiber surface

The free energy $\left(\Delta G_{a}^{d}\right)$ and enthalpy $\left(\Delta H_{a}^{d}\right)$ of adsorption with nonpolar probes were determined at five different temperatures by measuring the retention times, according to the IGC theory (Santos et al. 2001). The absolute values of $\Delta G_{a}^{d}$ (Fig. 3) and $\Delta H_{a}^{d}$ (Fig. 4) increase regularly with the number of $\mathrm{C}$ atoms in alkane chains of nonpolar probes, which confirms that the chromatographic experiments were adequately performed (Santos et al. 2001). The values of $\Delta G_{a}^{d}$ for MCC are considerably higher than those of the other fibers, in spite of its slight increase by the end of delignification (kappa no. 17 and 5).

Noticeable variations of $\Delta H_{a}^{d}$ as a function of the kappa number were observed for $n$-hexane and 


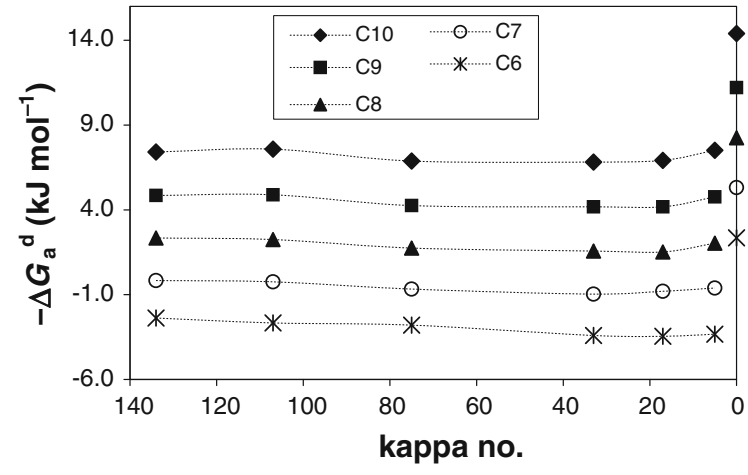

Fig. 3 Free energy of adsorption $\left(\Delta G_{a}^{d}\right)$ of the nonpolar probes versus the kappa number of the pulp samples at $40{ }^{\circ} \mathrm{C}$ (Datapoints at kappa numbers $=0$ are of microcrystalline cellulose)

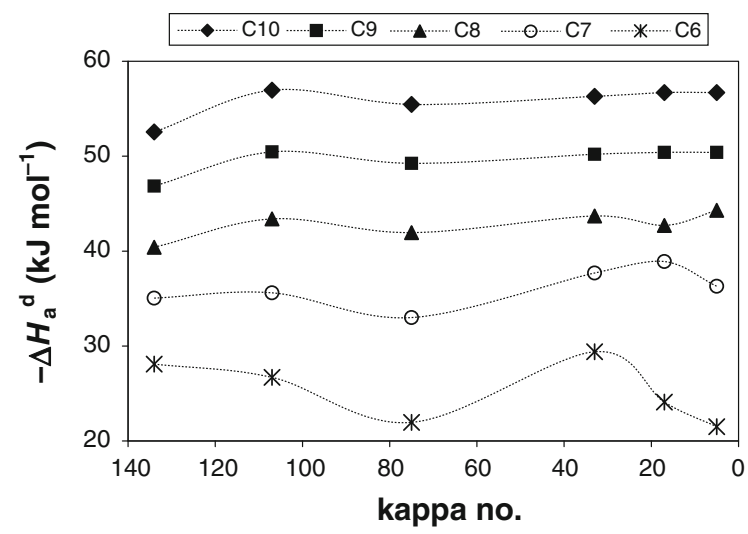

Fig. 4 The enthalpy of adsorption $\left(\Delta H_{a}^{d}\right)$ of nonpolar probes versus the kappa number of pulp samples

$n$-heptane (Fig. 4), while the values of $\Delta H_{a}^{d}$ for $\mathrm{C}_{9}$ and $\mathrm{C}_{10}$ were found to be predominantly constant.

Determination of specific interactions between polar probes and fiber surface

As an example of the specific interactions between the polar probes and the surface of the fibers, the results corresponding to the pulp with kappa number 17 are presented in Fig. 5. The specific free energy $\left(\Delta G_{a}^{s}\right)$ and the specific enthalpy $\left(\Delta H_{a}^{s}\right)$ of adsorption was also determined for all samples. The results are plotted in Figs. 6 and 7, respectively for $\Delta G_{a}^{s}$ and $\Delta H_{a}^{s}$.

As can be seen in Fig. 5, the $\Delta G_{a}^{s}$ values for dichloromethane and chloroform derived from these measurements are quite distinct, despite the very similar total interaction $\left(\Delta G_{a}\right)$ and donor/acceptor

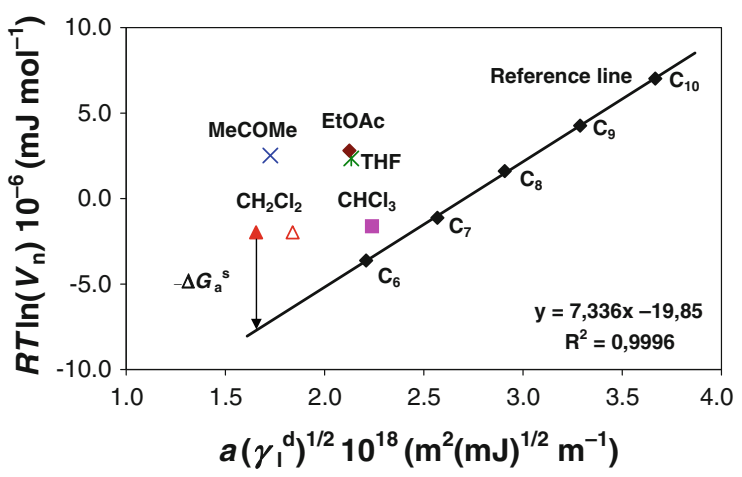

Fig. 5 Example of the specific interaction of polar probes with the fibers having a kappa number 17 , at $40{ }^{\circ} \mathrm{C}$

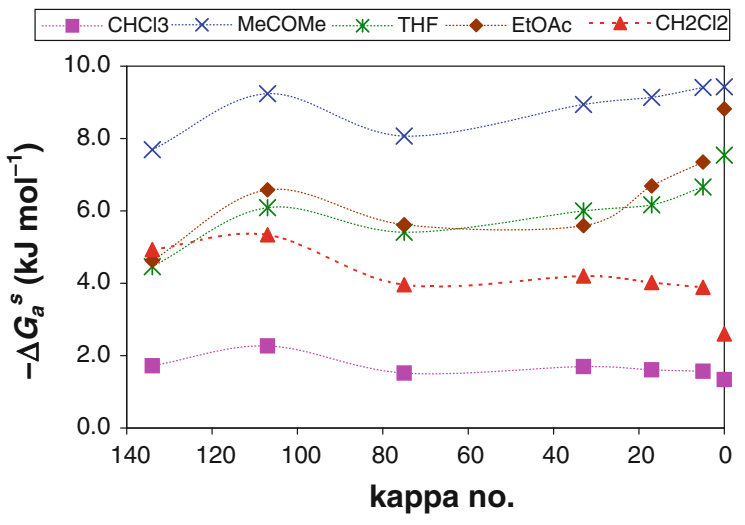

Fig. 6 Free energy of adsorption $\left(\Delta G_{a}^{s}\right)$ of the polar probes versus the kappa number of the pulp samples at $40{ }^{\circ} \mathrm{C}$ (Datapoints at kappa numbers $=0$ are of microcrystalline cellulose)

properties (Wålinder and Gardner 2000). Nonetheless it should be noted that experimental problems when using chloroform in IGC analyses are not uncommon, due to its closed and round-like shape. The specific interaction $\Delta G_{a}^{s}$ is calculated by the difference between the total interaction $\Delta G_{a}$ and the dispersive component $\Delta G_{a}^{d}$ :

$\Delta G_{a}^{s}=\Delta G_{a}-\Delta G_{a}^{d}=\mathrm{RT} \ln \left(\frac{V_{n, \mathrm{ref}}}{V_{n}}\right)$

The estimated cross-sectional area of the probe molecule, $a\left(\mathrm{CH}_{2} \mathrm{Cl}_{2}\right)$, plays a crucial role in the determination of specific interactions. Most authors in the field of pulp and papermaking fibers use the value 0.315 and $0.44 \mathrm{~nm}^{2}$ for dichloromethane and chloroform, respectively (Carvalho et al. 2005a; Santos and Guthrie 2005; Santos et al. 2001; 


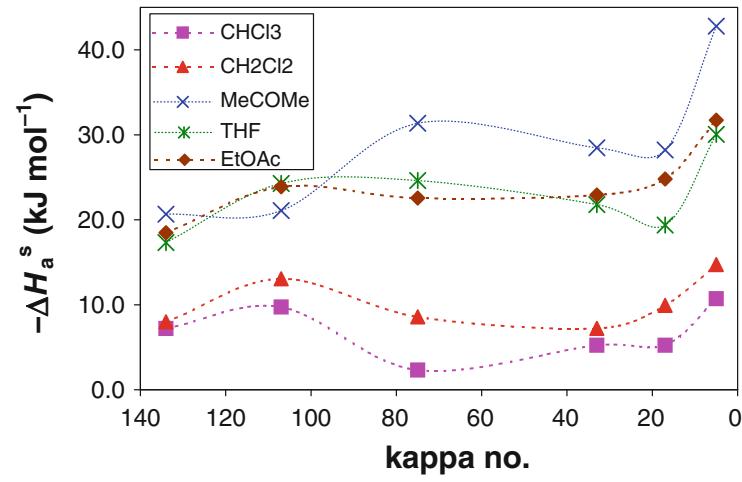

Fig. 7 The values of the enthalpy of adsorption for the polar probes, $\Delta H_{a}^{s}$, on surface of pulp samples with different kappa numbers

Wålinder and Gardner 2000). Enormous differences in $a\left(\mathrm{CH}_{2} \mathrm{Cl}_{2}\right)$ values from 0.14 to $0.46 \mathrm{~nm}^{2}$, determined by different methods, can be found in the literature. From these numbers, a mean value of $0.35 \mathrm{~nm}^{2}$ can be obtained (if the extreme values are omitted), which is more close to the value of chloroform (Hamieh and Schultz 2002). One would expect intuitively that the values of $a$, for these two molecules, should not differ too much, since the molecules are similar with respect to the composition and molecular dimensions. If the value $0.35 \mathrm{~nm}^{2}$ is taken instead of $0.315 \mathrm{~nm}^{2}$ for the $a\left(\mathrm{CH}_{2} \mathrm{Cl}_{2}\right)$, substantially lower value of $\Delta G_{a}^{s} \quad\left(\mathrm{CH}_{2} \mathrm{Cl}_{2}\right)$ is obtained, which lies more close to the values for chloroform (Figs. 5 and 6).

With few exceptions, the affinities of acidic probes remain essentially constant throughout the delignification. The values for MCC (kappa number 0) are more or less similar to the values of delignified fibers (kappa number 5) or even lower $\left(\mathrm{CH}_{2} \mathrm{Cl}_{2}\right)$. At the same time, for the amphoteric and particularly for the basic probes, an increase in $\Delta G_{a}^{s}$ for fibers containing a small amount of lignin is detected. This increase is even more pronounced for the enthalpy of adsorption (Fig. 7).

The results obtained with pure cellulose (MCC) confirm this tendency. It is apparent that the fibers composed predominantly or exclusively of carbohydrates exhibit an increased affinity to basic probes. The possible reason for the increased "acidity" of these fibers can be the high content of hydroxyl groups at the fibers surface (Carvalho et al. 2005a). Similar or even higher affinity to basic probes would

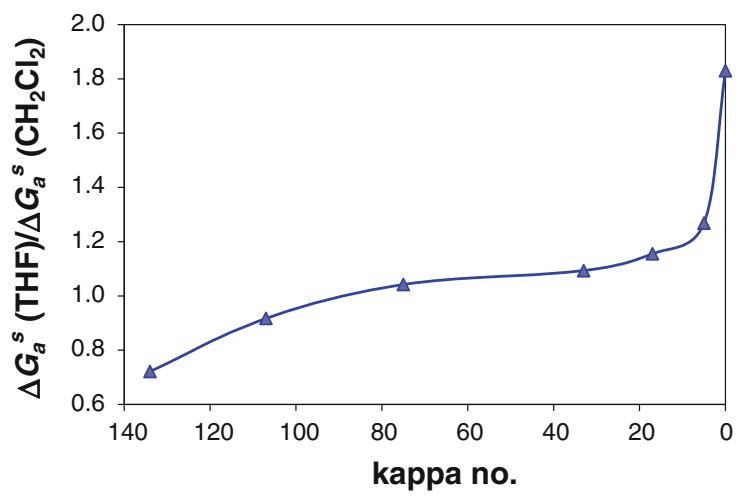

Fig. 8 The ratio $\Delta G_{a}^{s}(\mathrm{THF}) / \Delta G_{a}^{s}\left(\mathrm{CH}_{2} \mathrm{Cl}_{2}\right)$ versus the kappa number of the pulp samples at $40{ }^{\circ} \mathrm{C}$ (Data-points at kappa numbers $=0$ are of microcrystalline cellulose)

be expected for the carboxylic groups, which are several orders of magnitude more acidic. ${ }^{2}$ During the delignification process, the amount of carboxylic groups on our fibers varied substantially in the samples of the present study, being highest for the middle kappa numbers (from 75 to 5). Surprisingly, the affinities of basic probes to these fibers do not exhibit any correlation with the amount of carboxylic groups. Even the opposite, towards the end of delignification, where the amount of carboxylic groups begins to decline, "acidity" of the fibers increases (Figs. 7 and 8). The sample of microcrystalline cellulose with very low content of carboxylic groups shows the strongest interaction with THF and EtOAc.

The results presented in Figs. 6, 7 and 8 confirm that with the delignification process used in this study lignin is the prevailing substance at the fiber surface until the last stages of delignification, and therefore, for kappa numbers between 134 and 33, the fibers surface properties do not change considerably. At lower kappa numbers, lignin is removed and the carbohydrates become more exposed: the affinity of the basic probes begins to increase whereas that of the acidic probes tends to decrease. It is thus legitimate to conclude that the high affinity to basic probes is due to the carbohydrates, while lignin exhibits affinity to acidic probes.

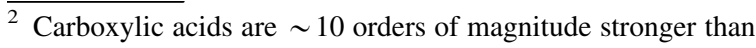
alcohols in aqueous medium. In gas phase, the difference in gas phase acidity of carboxylic acids and alcohols amounts to approx. $120 \mathrm{~kJ} \mathrm{~mol}^{-1}$ (Isaacs 1987).
} 
This considerable change of fiber surface properties only when the amount of lignin in fibers diminish to a very low content and the carbohydrate constituents become uncovered correlates well with the results reported in literature (Peterlin et al. 2009). In fact, the results of staining the same fibers with different types of dyes, show that the adsorption of some cationic dyes e.g. Methylene Blue and Crystal Violet correlates well with the amount of carboxylic groups. On the other hand, phthalocyanine cationic dye Astra Blue exhibits an entirely different behavior, which resembles largely the affinity of the basic probes (its adsorption begins to increase in the range of low lignin content).

\section{Conclusions}

During the delignification, $\gamma_{s}^{d}$ remains essentially constant until the very low content of lignin (about $1 / 10$ of the initial value), where a slight increase can be observed. The values are in accordance with the literature data for the similar samples of lignin rich materials. The values of $\gamma_{s}^{d}$ for isolated lignins are considerably higher, indicating a drastic change in properties during the isolation of lignin. $\Delta G_{a}^{d}$ increases linearly with the number of $\mathrm{C}$ atoms in alkane probes and keeps rather constant throughout the delignification.

Specific interactions, expressed as $\Delta G_{a}^{s}$, are also greatly unaffected by lignin content until the last stages of delignification. Acidic probes $\left(\mathrm{CH}_{2} \mathrm{Cl}_{2}\right.$ and $\mathrm{CHCl}_{3}$ ) exhibit a decrease in affinity, while basic ones (THF and EtOAc) show a substantial rise. The affinity of acetone, as an amphoteric probe, does not depend too much on the lignin content. With the depletion of the amount of lignin on fibers, the values of $\Delta G_{a}^{s}$, approach the values of microcrystalline cellulose. Despite the substantial variation in carboxylic group content during delignification, there was not observed a corresponding trend in the affinity of basic probes. Fibers, rich in carbohydrates and low in lignin exhibit an increased "acidity", i.e. increased affinity to basic and decreased affinity to acidic probes.

Acknowledgments We thank the Slovenian Research Agency for financial support, Prof. Matija Strlič, Faculty of Chemistry and Chemical Technology (P1-0153), for using their instruments for conductometric and potentiometric titrations, Prof. Pedro Fardim, Dr. Anna Sundberg, and Chunlin Xu, M. Sc. at Åbo Akademi University, Turku Finland, for carbohydrates and uronic acids analyses. We are grateful to Dr. Tjaša Drnovšek and Prof. Anton Perdih for helpful discussions. The work was supported in part by COST ACTION E 41 and COST ACTION E 54.

\section{References}

Abdmziem K, Passas R, Belgacem MN (2006) Inverse gas chromatography as a tool to characterize the specific surface area of cellulose fibers. Cellulose Chem Technol 40:199-204

Belgacem MN (2000) Characterization of polysaccharides, lignin and other woody components by inverse gas chromatography: a review. Cellulose Chem Technol 34:357-383 (and references cited therein)

Belgacem MN, Czeremuszkin G, Sapieha S (1995) Surface characterization of cellulose fibres by XPS and inverse gas chromatography. Cellulose 2:145-157

Belgacem MN, Blayo A, Gandini AJ (1996) Surface characterization of polysaccharides, lignin's, printing ink pigments, and ink fillers by inverse gas chromatography. Colloid Interface Sci 182:431-436

Börås L, Sjöström J, Gatenholm P (1997) Characterization of surfaces of CTMP fibers using inverse gas chromatography combined with multivariate data analysis. Nord Pulp Paper Res J 12:220-224

Buschle-Diller G, Inglesby MK, Wu Y (2005) Physicochemical properties of chemically and enzymatically modified cellulosic surfaces. Colloids Surf A Physicochem Eng Asp 260:63-70

Carvalho MG, Ferreira PJ, Santos JMRCA, Amaral JL, Figuerido MM (2005a) Effect of extended cooking and oxygen prebleaching on the surface energy of Eucalyptus globules kraft pulps. J Pulp Paper Sci 31:90-94

Carvalho MG, Santos JMRCA, Martins AA, Figuerido MM (2005b) The effects of beating, web forming and sizing on the surface energy of Eucalyptus globulus kraft fibres evaluated by inverse gas chromatography. Cellulose 12:371-383

Dorris GM, Gray DG (1980) Adsorption of $n$-alkanes at zero surface coverage on cellulose paper and wood fibers. J Colloid Interface Sci 77:353-362

Felix JM, Gatenholm P (1993) Characterization of cellulose fibers using inverse gas chromatography. Nord Pulp Paper Res J 8:200-203

Forss K, Fremer K-E (2000) The nature of lignin: a different view. ACS Symp Ser 100-116

Fowkes FM (1987) Role of acid-base interfacial bonding in adhesion. J Adhes Sci Technol 1:7-27

Hamieh T, Schultz J (2002) New approach to characterize physicochemical properties of solid substrates by inverse gas chromatography at finite dilution I. Some new methods to determine the surface areas of some molecules adsorbed on solid surfaces. J Chromatogr A 969:17-25

Isaacs NS (1987) Physical organic chemistry. Longman, Harlow, p 227 
Jacob PN, Berg JC (1994) Acid-base surface energy characterization of microcrystalline cellulose and two wood pulp fiber types using inverse gas chromatography. Langmuir 10:3086-3093

Kamdem DP, Riedl B (1991) Characterization of wood fibers modified by phenol-formaldehyde. Colloid Polymer Sci 269:595-603

Kubo S, Kadla JF (2005) Hydrogen bonding in lignin: a fourier transform infrared model compound study. Biomacromolecules 6:2815-2821

Kunaver M, Zadnik J, Planinšek O, Srčič S (2004) Inverse gas chromatography - a different approach to characterization of solids and liquids. Acta Chim Slov 51:373-394

Li J, Gellerstedt G (1998a) Kinetics and mechanism of kappa number determination. Nord Pulp Paper Res J 13:147-152

Li J, Gellerstedt G (1998b) On the structural significance of kappa number measurement. Nord Pulp Paper Res J 13:153-158

Matuana LM, Balatinecz JJ, Park CB, Woodhams RT (1999) Surface characteristics of chemically modified newsprint fibers determined by inverse gas chromatography. Wood Fiber Sci 31:116-127

Papirer E, Brendle E, Balard H, Vergelati C (2000) Inverse gas chromatography investigation of the surface properties of cellulose. J Adhesion Sci Technol 14:321-337

Peterlin S, Drnovšek T, Perdih A, Dolenc D (2009) Surface characterization of stepwise oxidized spruce thermomechanical pulp samples by different analytical methods. Cellulose 16:833-839

Santos JMRCA, Guthrie JT (2005) Analysis of interactions in multicomponent polymeric systems: the key-role of inverse gas chromatography. Mater Sci Eng R Rep 50:79-107

Santos JMRCA, Gil MH, Portugal A, Guthrie JT (2001) Characterization of the surface of a cellulosic multipurpose office paper by inverse gas chromatography. Cellulose 8:217-224

Santos JMRCA, Fagelman K, Guthrie JT (2002) Characterization of the surface Lewis acid-base properties of poly(buthylene terephthalate) by inverse gas chromatography. J Chromatogr A 969:111-118

Schultz J, Lavielle L, Martin C (1987) The role of the interface in carbon fibre-epoxy composites. J Adhesion 23:45-60

Shen W, Parker IH (1999) Surface composition and surface energetics of various eucalypt pulps. Cellulose 6:41-55

Shen W, Yao W, Li M, Parker I (1998) Characterization of eucalypt fiber surface using inverse gas chromatography and X-ray photoelectron spectroscopy. Appita J 51: $147-151$

Sundberg A, Sundberg K, Lillandt C, Holmbom B (1996) Determination of hemicelluloses and pectens in wood and pulp fibers by acid methanolysis and gas chromatography. Nord Pulp Paper Res J 11:216-291

Tze WTY, Wålinder MEP, Gardner DJ (2006) Inverse gas chromatography for studying interaction of materials used for cellulose fiber/polymer composites. J Adhesion Sci Technol 20:743-759

Wålinder MEP, Gardner DJ (2000) Surface energy of extracted and non-extracted Norway spruce wood particles studied by inverse gas chromatography (IGC). Wood Fiber Sci $32: 478-488$ 